
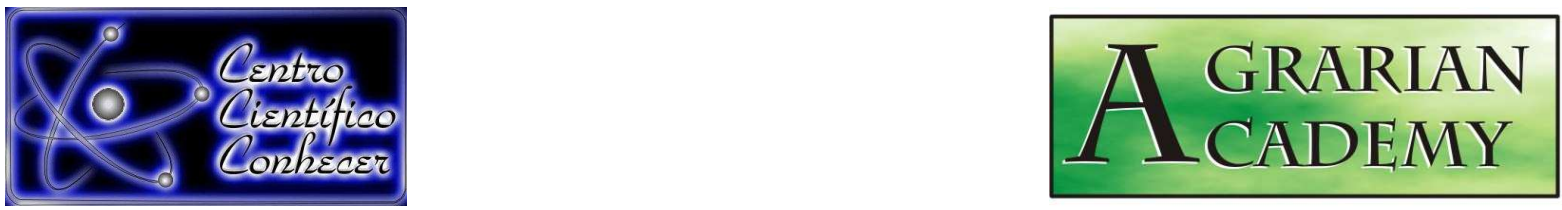

\title{
TRILHAS ECOLÓGICAS DA ÁREA DE PROTEÇÃO AMBIENTAL MUNICIPAL DO INHAMUM E SEUS ASPECTOS FLORÍSTICOS, MARANHÃO, BRASIL
}

Guilherme Sousa da Silva ${ }^{1}$, Domingos Lucas dos Santos Silva², Maria Lindalva Alves da Silva ${ }^{3}$, Werton Francisco Nobre Silva ${ }^{4}$, Gonçalo Mendes da Conceição ${ }^{5}$

1. Bolsista Técnico do Laboratório de Biologia Vegetal/LABIVE, Universidade Estadual do Maranhão/UEMA, Centro de Estudos Superiores de Caxias/CESC, PósGraduando em Educação e Ensino de Ciências no Instituto Federal do Maranhão

Campus Caxias - Maranhão/Brasil (guilhermecx.cx@hotmail.com)

2. Mestre em Biodiversidade, Ambiente e Saúde, CESC/UEMA, Laboratório de Biologia Vegetal/LABIVE, Caxias/MA, Brasil.

3. Mestranda do Programa de Pós-Graduação em Biodiversidade, Ambiente e Saúde/PPGBAS, Laboratório de Biologia Vegetal/LABIVE, CESC/UEMA, Caxias/MA, Brasil

4.Graduado em Geografia Licenciatura, CESC/UEMA, Laboratório de Biologia Vegetal/LABIVE, Caxias/MA, Brasil.

5. Professor Dr. do Centro de Estudos Superiores de Caxias/CESC, da Universidade Estadual do Maranhão/UEMA, Programa de Pós-Graduação em Biodiversidade, Ambiente e Saúde/PPGBAS, Maranhão/Brasil

Recebido em: 05/12/2016 - Aprovado em: 15/12/2016 - Publicado em: 31/12/2016 DOI: 10.18677/Agrarian_Academy_2016b13

\begin{abstract}
Esta pesquisa teve como objetivo caracterizar a composição florística das trilhas ecológicas visitadas no interior da APA do Inhamum. Para identificação das trilhas foram realizadas excursões a APA do Inhamum no período de Julho à Setembro de 2016, para determinar as principais trilhas ecológicas da área de estudo, onde foram marcadas 11 trilhas ecológicas, obtendo as coordenadas geográficas, altitude e principais características cartográficas. Após a determinação das trilhas, ocorreu a caraterização vegetacional de cada trilha, onde foram observados: o tipo de fisionomia, o dossel, principais populações vegetais, a antropização ou não da trilha, e as principais espécies diagnosticas em cada local. Nas trilhas ecológicas da Área de Proteção Ambiental Municipal do Inhamum, foram identificadas 180 espécies, pertencentes a 51 famílias. O estudo das trilhas ecológicas da APA do Inhamum possibilitou um campo de estudo vasto em virtude de sua extensão e riqueza de espécies, com a perspectiva de promover atividades pedagógicas na garantia da difusão da prática da educação ambiental como ferramenta de transformação de novas atitudes e comportamento quanto ao uso dos recursos naturais.
\end{abstract}

PALAVRAS-CHAVE: Educação ambiental, Interpretação ambiental, Recurso naturais. 


\title{
ECOLOGICAL TRACKS IN THE MUNICIPAL ENVIRONMENTAL PROTECTION AREA OF INHAMUM AND ITS FLORISTIC ASPECTS, MARANHÃO, BRAZIL
}

\begin{abstract}
The objective of this research was to characterize the floristic constitution of the ecological trails visited inside the Inhamum APA. In order to identify the trails, there were excursions to the Inhamum APA from July to September 2016 to determine the main ecological trails of the study area, where 11 ecological trails were marked, obtaining the geographical coordinates, altitude and main cartographic characteristics. After the determination of the trails, the vegetative characterization of each trail was observed, where the physiognomy type, the canopy, the main plant populations, the anthropization or not of the trail, and the main diagnostic species were observed at each site. In the ecological trails of the Inhamum Municipal Environmental Protection Area, 180 species were identified, belonging to 51 families. The study of the ecological trails of the APA of Inhamum allowed a vast field of study due to its extension and species richness, with the perspective of promoting pedagogical activities in the guarantee of the diffusion of the practice of the environmental education as tool of transformation of new attitudes and behavior The use of natural resources.
\end{abstract}

KEYWORDS: Environmental education, Natural resources, Environmental interpretation.

\section{INTRODUÇÃO}

De acordo com Sistema Nacional de Unidades de Conservação (SNUC), Lei Federal no 9.985/00, (BRASIL, 2000), a Área de Proteção Ambiental Municipal do Inhamum, é uma unidade de proteção classificada na categoria de uso sustentável dotada de atributos abióticos, bióticos, estéticos e/ou culturais com objetivos de proteger a diversidade biológica e assegurar a ocupação humana.

Dentre os objetivos da criação das unidades de conservação, de acordo com a Lei no 9.895/2000 estar relacionado ao fato de promover ações voltadas para Educação Ambiental (EA), possibilitando a estudantes, professores e comunidades em geral a construção de novos valores e mudanças de comportamentos voltados para um mundo ecologicamente mais sustentável. Neste sentido, a EA, segundo CARVALHO DE LIMA (2008), é um processo educativo com a formação de cidadãos com capacidade de compreensão e atuação no mundo de forma ética e consciente. Nas considerações de CAMARGO (2002), a EA tem como objetivo primordial garantir a sociedade uma forma de sobrevivência coerente, sustentável e democrática, com igualdade e equidade para todos.

A APA do Inhamum proporciona à comunidade acadêmica "caminhos" que os direcione na realização de pesquisas e maior contato com a natureza. Nesta perspectiva, LIMA (1998) citado por IKEMOTO et al., (2009), destacam que estes caminhos são conhecidos como trilhas ecológicas. De acordo com o autor as trilhas são instrumentos pedagógicos que têm um caráter educativo e que podem ser classificadas como interpretativas, monitoradas simples ou guiada e/ou monitoradas com guia associada a outras programações.

Na visão de SILVA et al., (2012), atividades pedagógicas com uso de trilhas ecológicas são práticas de educação ambiental que objetivam o propósito de difundir valores e resgate histórico e cultural de áreas naturais e ao mesmo tempo oportunizar a percepção ambiental do local visitado. Corroborando com as ideias supracitadas, ARANCíBIA \& CAVALCANTE (2005), defendem que as trilhas ecológicas exercem uma influência no processo de conservação do ambiente, uma 
vez que oferecem ao ser humano, um momento de estar em contato com a natureza, posteriormente, pode-se resultar desse contato, uma mudança de comportamento do ser humano com o ambiente físico/natural.

As trilhas têm um papel fundamental para o contato das pessoas com o ambiente natural, elas sofrem constantemente a interferência humana e provocam nas pessoas impactos de ordem comportamental, visual, estético, sonoro, sono e olfativo (RODRIGUES \& TORVOES, 2007). Desta forma o presente trabalho teve como objetivo caracterizar a constituição florística das trilhas ecológicas visitadas no interior da APA do Inhamum, para conhecimento e divulgação de práticas que promovam a Educação Ambiental.

\section{MATERIAL E MÉTODOS}

A área de Proteção Ambiental Municipal do Inhamum é considerada Patrimônio Municipal de Caxias. A área está localizada entre as coordenadas -04은 53' $30^{\prime \prime}$ de Latitude S e $-43^{\circ}$ 24' 53" de Longitude W, a margem da BR-316, a aproximadamente $2 \mathrm{~km}$ do perímetro urbano de Caxias/MA (Figura 1). Foi criada pela Lei Municipal 1.46/2001, do dia 04 de julho de 2001 e possui uma área de aproximadamente 4.500 hectares, tendo a configuração paisagística fisionomicamente o Cerrado, com dois estratos, um arbóreo/arbustivo e outro composto por gramíneas em áreas planas, enquanto que nas depressões têm-se buritizais associadas aos cursos hídricos (CAXIAS, 2001).

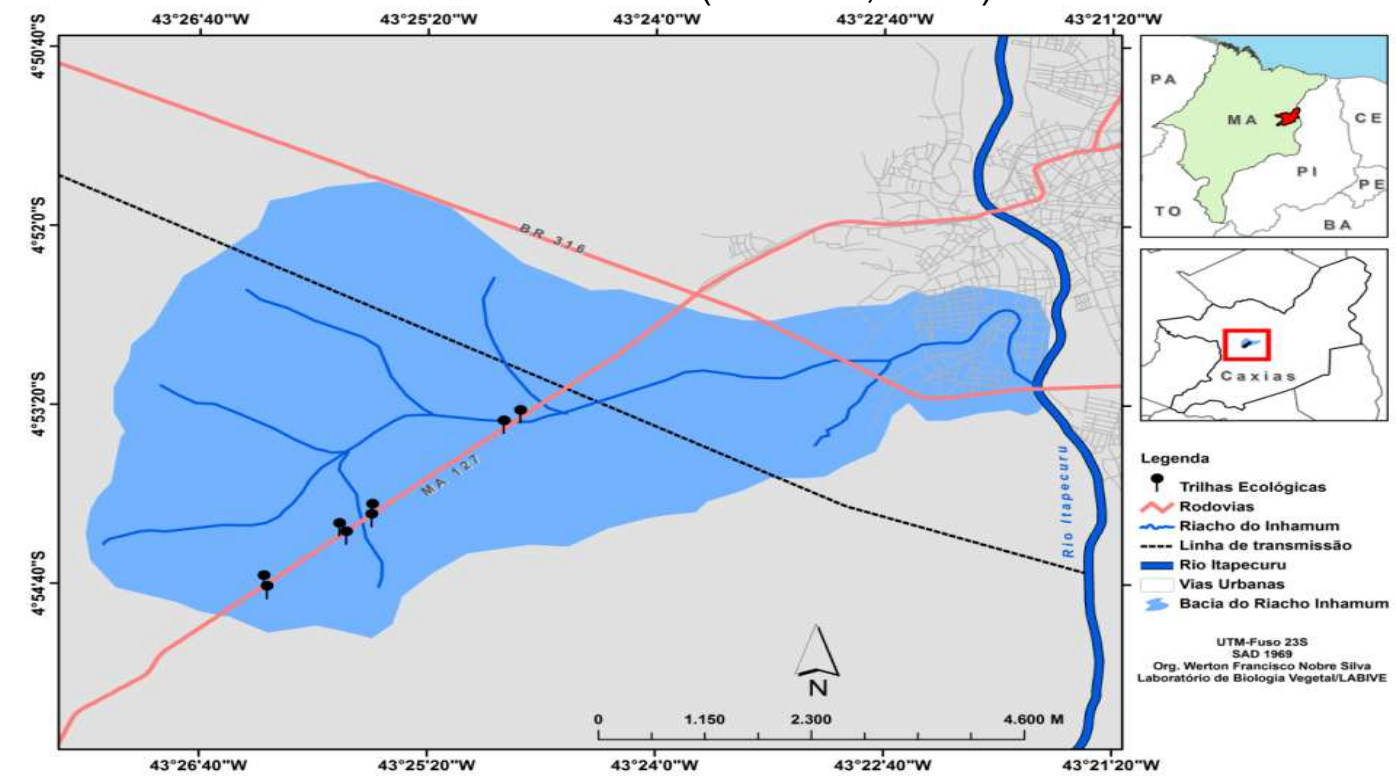

FIGURA 1. Mapa com as trilhas ecológicas da APA - Inhamum. Fonte: IBGE, 2006. Organização: SILVA,(2016).

O clima predominante da área é o Tropical sub-úmido AW, com duas estações distintas, verões chuvosos e invernos secos. Segundo ARAÚJO (2012) a área caracteriza-se por apresentar índices pluviométricos regulares entre $1.600 \mathrm{e}$ $1.800 \mathrm{~mm}$, as temperaturas, mínimas, médias e máximas, são normalmente elevadas. A média anual é superior a $24^{\circ} \mathrm{C}$. A hidrog rafia da APA do Inhamum apresenta um riacho principal, que recebe o mesmo nome da APA, e subafluentes, fazendo parte da rede hidrográfica da bacia do rio Itapecuru. O riacho do Inhamum constitui-se como um riacho de segunda ordem e de regimes permanentes, suas águas se localizam à margem esquerda do rio Itapecuru na MA-127 sentido Caxias/São João do Sóter. A geomorfologia da área está localizada na bacia 
sedimentar do Meio Norte com áreas de depressões e com presença marcante de areia quartzosa e solos aluviais nas proximidades do percurso d'água.

Foram realizadas excursões a APA do Inhamum no período de Julho à Setembro de 2016, para determinar as principais trilhas ecológicas encontradas na área de estudo que são utilizadas como pontos de coleta para espécies vegetais. Foram marcadas 11 trilhas ecológicas, com o auxílio do GPS, obtendo as coordenadas geográficas, altitude e principais características cartográficas de cada trilha ecológica. Após a determinação das trilhas, ocorreu a caracterização vegetacional de cada trilha, onde foram observados: o tipo de fisionomia, o dossel, principais populações vegetais, a antropização ou não da trilha, e a principais espécies diagnosticadas em cada local.

Para caracterização da vegetação, determinou-se para coleta e identificação os grupos de Briófitas, Licófitas, Monilófitas e Angiospermas. O material de Briófitas foi coletado manualmente e/ou com canivete e espátula para a remoção das amostras, acondicionados em sacos de papel pardo e sacos plásticos, sendo anotados, em caderneta de campo, dados relativos às espécies. Todo o material foi seco em temperatura ambiente baseando os processos de armazenamento e Herborização de YANO (1984). Para a coleta de Licófitas, Monilófitas e Angiospermas, o material botânico foi coletado com o auxílio de tesoura de poda e desplantador, onde o material obtido foi acondicionado em sacos plásticos e etiquetado de acordo com a sequência de coleta. Para cada espécime foi realizada uma série de anotações como data e local de coleta, o nome do coletor, e as características físicas do ambiente, hábito e característica da planta, cor e textura das folhas, ausência ou não de esporos, disposição dos soros, presença ou ausência de flor e fruto. Depois das coletas, os espécimes vegetais foram prensados entre folhas de jornal, papelão e secos a temperatura ambiente. Com o material desidratado, os mesmos foram fixados em cartolina, de tamanho apropriado $(28 \times 42$ $\mathrm{cm})$, onde receberam etiquetas com dados informativos, constituindo a exsicata.

\section{RESULTADOS E DISCUSSÃO}

Foram caracterizadas as 11 trilhas pertencentes a APA, foram agrupadas através da semelhança de características (Figura 2). As trilhas 1 e 2 (1454'39.03"S - 4326'17.05"O/ 2- 454'37.07"S/ 432 6'17.06"O), apresenta dois tipos de fisionomia de Cerrado sujo e Mata de Galeria, com arbustos e árvores dispersas no decorrer da trilha com grandes quantidades de gramíneas, com dossel aberto chegando em alguns pontos semiaberto até tornar-se fechado nas Matas de Galeria, as principais famílias predominantes são Poaceae, Rubiaceae e algumas Fabaceae e uma considerável presença de Myrtaceae. Sendo uma trilha bastante visitada, a mesma apresenta um considerável nível de antropização.

Em ecossistemas naturais do Brasil, a conservação da diversidade biológica representa um dos maiores desafios, isto deve-se as fortes ações antrópicas, dessa forma, estudos florísticos é de fundamental importância por subsidiar informações indispensáveis para o manejo e regeneração das formações florestais (CHAVES et al. 2013).

As trilhas 3 e 4 (3- 454'15.14"S - 4325'49.29"O / 4- 454'14.47"S 4325'50.34"O), são trilhas com três tipos de fisionomias a de Cerrado limpo, Cerrado sujo e Mata de Galeria. As trilhas iniciam-se com grande predominância de gramíneas com poucos arbustos, mas à medida que se adentra ao interior da área, o cerrado sujo torna-se um espaço de mata de galeria. As famílias Fabaceae, 
Cyperaceae, Poaceae, Rubiaceae, Melastomataceae e Apocynaceae são exemplares vegetacionais mais representativos, com um nível de antropização moderado, passando por ataque de queimadas no período seco. O dossel é de aberto a fechado em trechos da mata de galeria.

Portanto, quando fala-se em trilhas, MAGRO (1999), lembra que as mesmas promovem a transmissão de conhecimentos em momentos de lazer e se torna interessante esses momentos tanto do ponto de vista educativo quanto recreativo. Para o autor, as trilhas contribuem para o manejo de áreas protegidas pelo fluxo de visitantes e evita que outras áreas no interior da unidade de conservação sejam visitas e afetadas pelo impacto dos usuários.

As trilhas 5, 6, 7, 8 e 9 (5; 6 - 454'7.22"S - 432 25'40.27"O / 7; 8; 9454'5.31"S - 4325'39.39"O) são típicas de Cerrado com as fisionomias de Cerrado sujo a fragmentos de Cerradão, com árvores e arbustos predominantes a chegar pontos com consideráveis taxas de serapilheira, sem a presença de corpos hídricos, com dossel aberto à semiaberto. A vegetação é composta por gramíneas, ervas, arbusto e árvores das famílias Fabaceae, Areacaceae, Caryocaraceae, Rubiaceae, entre outras espécies de Famílias distintas. As áreas não têm uma ação antrópica significativa, mas no período seco, acaba por ser o das queimadas naturais e criminosas na área de estudo.

Para a conservação do Meio Ambiente, vários fatores podem ser considerados, mas um meio, que ajuda na preservação e utilização de maneira sustentável dos recursos naturais é a Educação Ambiental (LIMA, 2015). Conforme SERPE \& ROSSO (2010), um dos espaços que se trabalha a Educação Ambiental são áreas de conservação, que são áreas de visitações, pesquisa e atividades de educativas (UNIVERSIDADE DO VALE DO PARAÍBA, 2002).

As trilhas 10 e 11(10-453'25.51"S - 4324'51.54"O/ 11- 453'29.66"S 4324'57.29"O) são mais afastadas das demais, e pos suem fisionomias de Cerrado sujo a fragmentos de mata de Galeria, que se estabelecem apenas no período chuvoso com a formação de lagos e brejos temporários. A mesma apresenta fragmentos de Buritizais e algumas populações de samambaias. A vegetação é composta por Fabaceae, Sapindaceae, Lecythidaceae, Rubiaceae e outras famílias botânicas. O nível de antropização é considerável, pois no local vivem algumas pessoas o que leva a alterações das fisionomias.

Nas trilhas ecológicas da Área de Proteção Ambiental Municipal do Inhamum, foram identificadas 180 espécies, pertencentes a 51 famílias. Destas, 50 espécies e 24 famílias são pertencentes as criptógamas (Briófitas, Monilófitas e Licófitas) e 130 espécies, 91 gêneros e 26 famílias pertencem às fanerógamas/angiospermas (Quadro 1).

A APA - Inhamum apresenta uma diversidade de espécies típicas do Cerrado. Embora as trilhas da APA apresentem uma diversidade florística, a vegetação encontra-se modificada, considerando que vem sofrendo fortes impactos ambientais. No entanto, estes impactos acontecem de forma natural ou por ações antrópicas. Conforme ARAÚJO (2002), a degradação dos ambientes ocorre por meio de poluição por moradores que vivem ao redor da área e por meio de descartes de resíduos sólidos e líquidos de indústrias, dentre outros fatores. No entanto, estes impactos devem ser evitados com a finalidade de garantir a conservação e preservação desses ambientes naturais. 


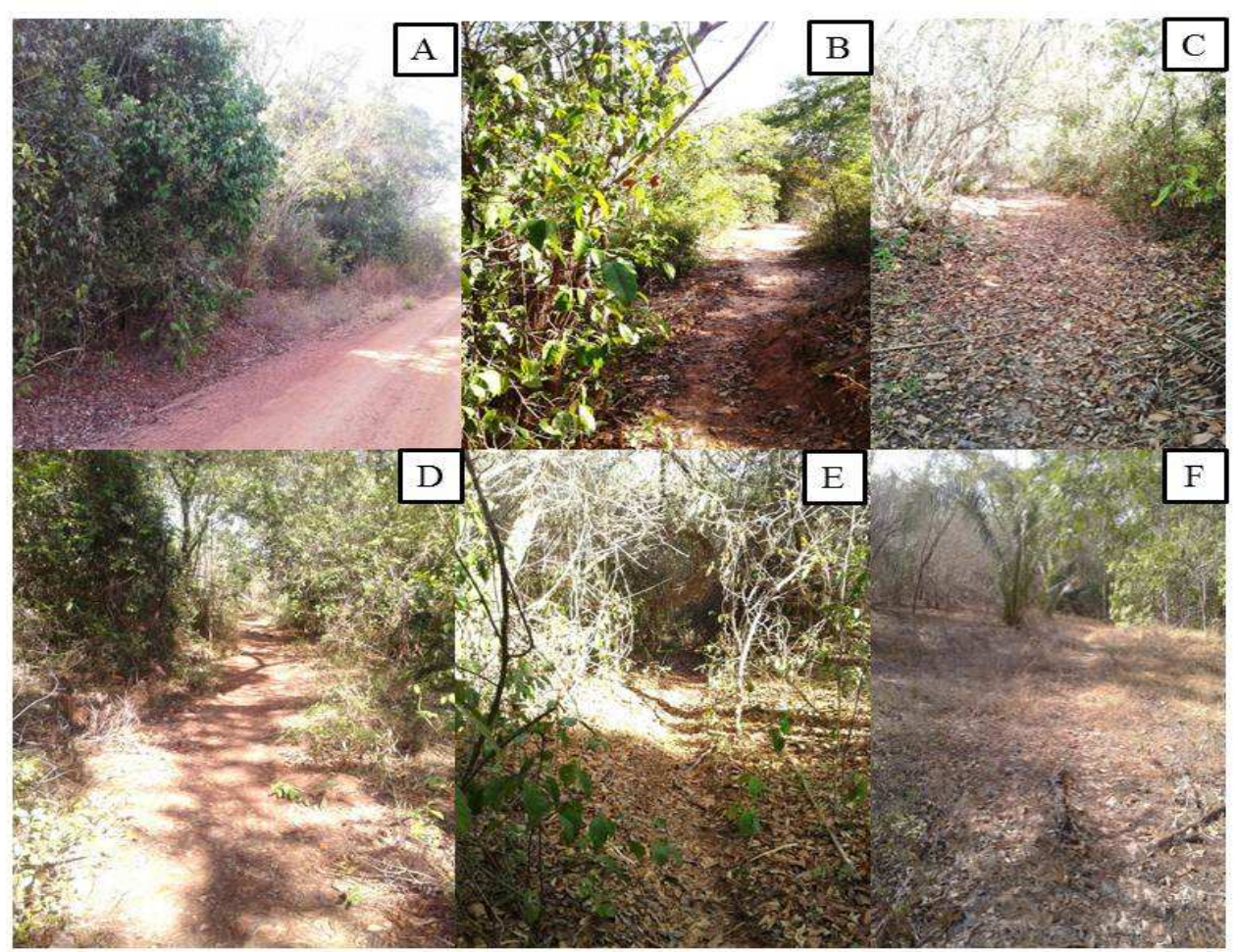

FIGURA 2. Trilhas ecológicas da APA do Inhamum, com os aspectos fisionômicos vegetação. A- Trilha da casa 2; BTrilha dos alambiques; C- Trilha da casa 1; D- Trilha dos Coités 1; E-Trilha das Cacimbas; F - Trilha dos Coités 2. Fonte: SILVA, (2016).

QUADRO 1. Espécies de vegetais encontradas ao longo das trilhas ecológicas da APA - Inhamum, Caxias, Maranhão, Brasil.

\begin{tabular}{|c|c|c|}
\hline GRUPOS & FAMÍLIA & ESPÉCIE \\
\hline \multirow{20}{*}{ Briófita } & Bartramiaceae & Philonotis sphaerocarpa (Hedw.) Brid. \\
\hline & \multirow[t]{2}{*}{ Bryaceae } & $\begin{array}{l}\text { Brachymenium exile (Dozy \& Molk.) Brosh } \\
\text { \&Lac. }\end{array}$ \\
\hline & & Gemmabryum caespiticium Hedw. \\
\hline & \multirow[t]{4}{*}{ Calymperaceae } & Calymperes erosum Müll. Hal. \\
\hline & & Calymperes palisotii Schwägr. \\
\hline & & Octoblepharum albidumHedw. \\
\hline & & Octoblepharum cilindricum Mont. \\
\hline & \multirow[t]{2}{*}{ Dicranaceae } & $\begin{array}{l}\text { Campylopus heterostachys (Hampe) A. } \\
\text { Jaeger }\end{array}$ \\
\hline & & Campylopus savannarum (Müll. Hal.) Mitt. \\
\hline & Ditrichaceae & Garckea flexuosa (Griff.) Margad. \& Nork. \\
\hline & Erpodiaceae & Erpodium coronatum (Hook. \& Wilson) Mitt. \\
\hline & \multirow[t]{3}{*}{ Fissidentaceae } & Fissidens ornatus Herzog \\
\hline & & Fissidens perfalcatus Broth. \\
\hline & & Fissidens submarginatus Bruch. \\
\hline & \multirow[t]{2}{*}{ Hypnaceae } & Isopterygium tenerifolium Mitt. \\
\hline & & Isopterygium tenerum (Sw.) Mitt. \\
\hline & \multirow[t]{4}{*}{ Frullaniaceae } & Frullania caulisequa (Nees) Ness \\
\hline & & Frullania gibbosa Ness \\
\hline & & Acrolejeunea emergens (Mitt.) Steph. \\
\hline & & Acrolejeunea torulosa (Lehm \& Lindenb.) \\
\hline
\end{tabular}




\begin{tabular}{|c|c|c|}
\hline & & Schiffn \\
\hline & & Aphanolejeunea truncatifolia Horik. \\
\hline & Lejeuneaceae & Cheilolejeunea rigidula (Mont.) R. M. Schust. \\
\hline & & $\begin{array}{l}\text { Lejeunea caulicalyx (Steph.) E. Reiner \& } \\
\text { Goda }\end{array}$ \\
\hline & & Lejeunea laetevirens Nees \& Mont. \\
\hline & & Lejeunea phyllobola Nees \& Mont. \\
\hline & Lepidozeaceae & Zoopsidella macella (Steph.) R.M.Schust. \\
\hline & Pottiaceae & Hyophila involuta (Hook.) A. Jaeger. \\
\hline & Rachitheciaceae & Zanderia octoblepharis (A. Jaeger) Goffinet \\
\hline & & Sematophyllum galipense (Müll. Hal.) Mitt. \\
\hline & & Sematophyllum subsimplex (Hedw.) Mitt. \\
\hline & & $\begin{array}{l}\text { Trichosteleum papilosun (Hornsch.) A. } \\
\text { Jaeger. }\end{array}$ \\
\hline & Sematophyllaceae & $\begin{array}{l}\begin{array}{l}\text { Trichosteleum hornschuchii (Hampe) A. } \\
\text { Jaeger }\end{array} \\
\text { J. }\end{array}$ \\
\hline & & $\begin{array}{l}\begin{array}{l}\text { Trichosteleum subdemissum (Besch.) A. } \\
\text { Jaeger }\end{array} \\
\text { J. }\end{array}$ \\
\hline & & Trichosteleum vicentinum (Mitt.) A. Jaeger \\
\hline & Stereophyllaceae & $\begin{array}{l}\text { Entodontopsis leucostega (Brid.) W.R. Buck } \\
\text { \& Ireland }\end{array}$ \\
\hline & Thuidiaceae & Pelekium involvens (Hedw.) \\
\hline & Blechnaceae & Blechnum serrulatum Rich. \\
\hline & Lomariopsidaceae & Nephrolepis biserrata (Sw.) Schott. \\
\hline & & Nephrolepis rivularis (Vahl.) Mett.ex. Krug. \\
\hline Monilófita & Dennstaedtiaceae & Lindsaea lancea (L.) Beddome \\
\hline & Hymenophyllaceae & Trichomanes cristatum Kaulf. \\
\hline & Polypodiaceae & Phlebodium aureum (L.) J. Sm. \\
\hline & Pteridaceae & Adiantum deflectens Mart. \\
\hline & & Pityrogramma calomelanos (L.) Link. \\
\hline & Lygodiaceae & Lygodium venustum Sw. \\
\hline & & Lygodium volubile Sw. \\
\hline & Thelypteridaceae & Thelypteris cf. interrupta (Willd.) K. Iwats. \\
\hline & & Thelypteris patens (Sw.) Small. \\
\hline & & Thelypteris reticulata (L.) Proctor. \\
\hline Licófita & Lycopodiaceae & Lycopodiella cernua (L.) Pichi-Sermolli. \\
\hline & Anacardiaceae & Anacardium occidentale L. \\
\hline & & Astronium fraxinifolium Schott. \\
\hline & & Myracrodruon urundeuva Allem. \\
\hline & Annonaceae & Annona dioica St. Hil. \\
\hline & Apocynaceae & $\begin{array}{l}\text { Aspidosperma spruceanum Benth. Ex. M. } \\
\text { Arg. }\end{array}$ \\
\hline & & $\begin{array}{l}\text { Himatanthus obovatus (M. Arg.) R. E. } \\
\text { Woodson }\end{array}$ \\
\hline & & Hancornia speciosa Gomez \\
\hline & Asteraceae & Vernonia sp \\
\hline & Bignoniaceae & Tabebuia impetiginosa (Mart. ex. DC.). \\
\hline & & Zeyheria montana Mart. \\
\hline & Boraginaceae & Cordia sp \\
\hline & Burseraceae & Protium heptaphyllum (Aulbl.) Marchand. \\
\hline & Caryocaraceae & Caryocar coriace um Wittm. \\
\hline Angiosperma & Chrysobalanaceae & Exellodendron cordatum (Hook.f.) Prance \\
\hline & & Hirtella glandulosa Spreng. \\
\hline
\end{tabular}

AGRARIAN ACADEMY, Centro Científico Conhecer - Goiânia, v.3, n.06; p. 92 2016 


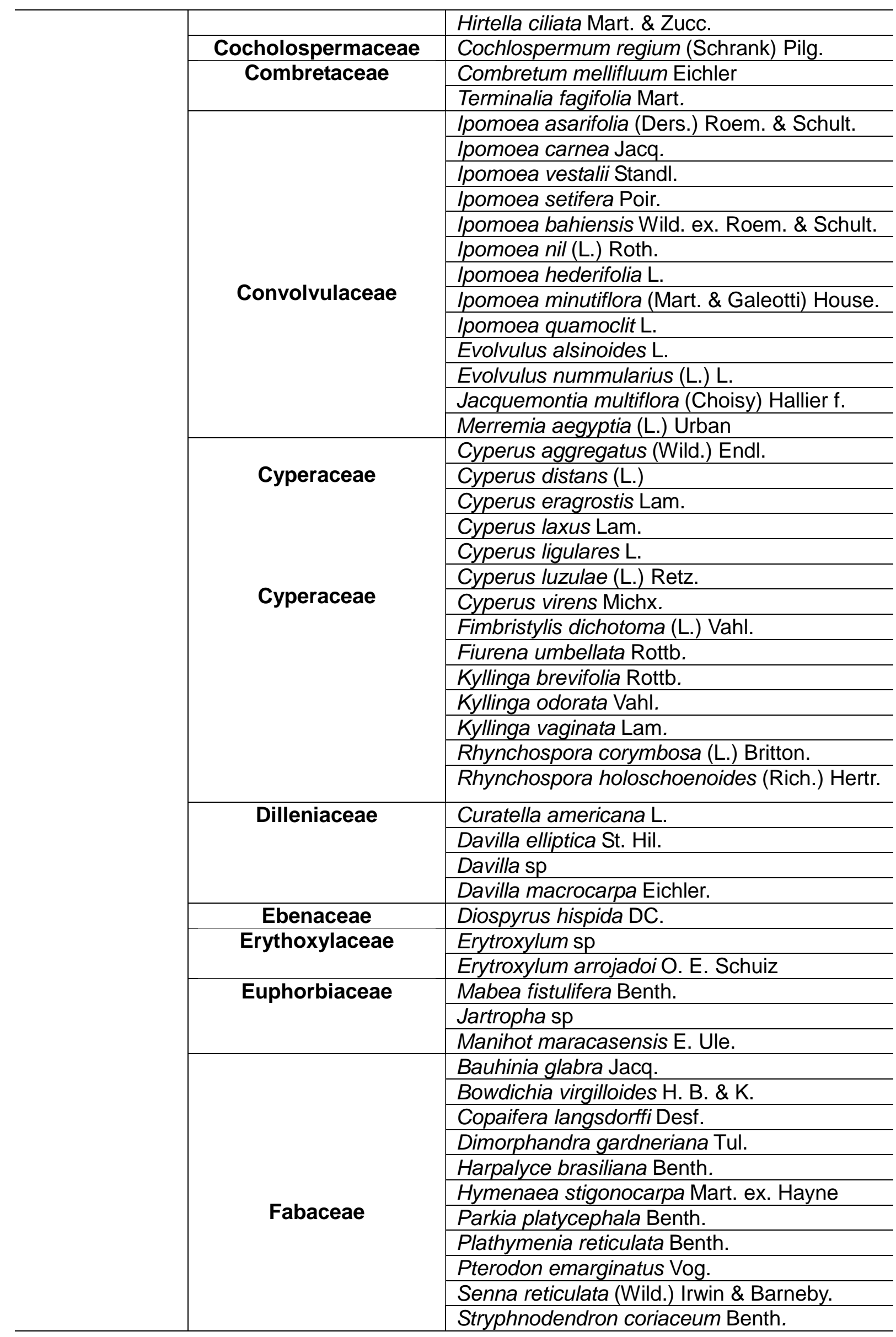




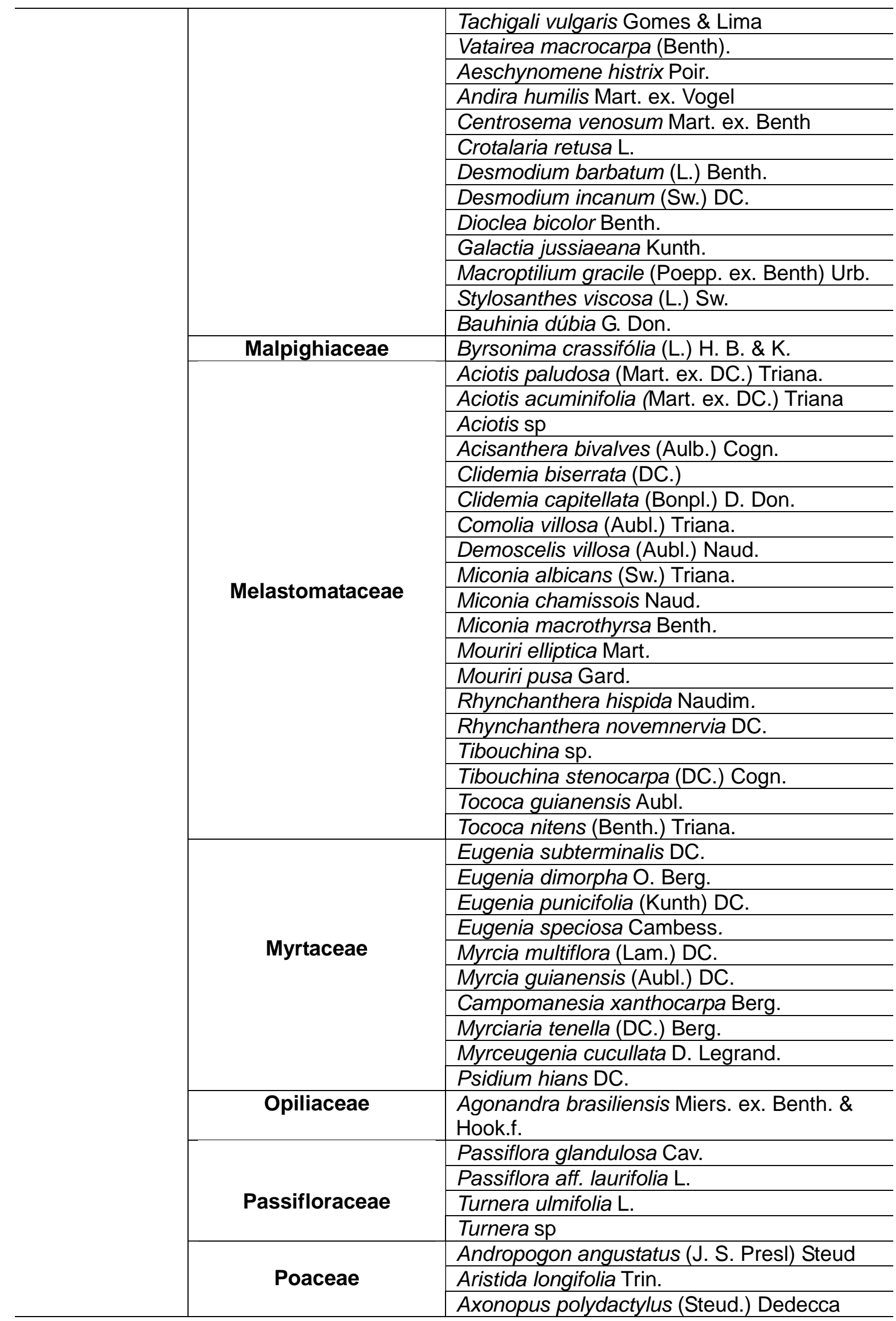




\begin{tabular}{|c|c|c|}
\hline & \multirow{12}{*}{$\begin{array}{c} \\
\text { Rubiaceae } \\
\text { Volchysiaceae }\end{array}$} & \multirow{3}{*}{$\begin{array}{l}\text { Chaetium festucoides Ness. } \\
\text { Megathyrsus maximus (Jacq.) B.K.Simon \& } \\
\text { S.W.L.Jacobs } \\
\text { Panicum pilosum Sw. }\end{array}$} \\
\hline & & \\
\hline & & \\
\hline & & Paspalum gardnerianum Ness. \\
\hline & & Sacciolepis angustissima (Steud.) Kuhlm. \\
\hline & & Streptostachys asperifolia Desv. \\
\hline & & Trachypogon spicatus (L. F.) Kuntze. \\
\hline & & Alibertia sp \\
\hline & & Alibertia edulis (L. C. Rich.) A. Rich. ex. DC. \\
\hline & & Qualea grandiflora Mart. \\
\hline & & Qualea parviflora Mart. \\
\hline & & Salvertia convallariaeodora St. Hil. \\
\hline
\end{tabular}

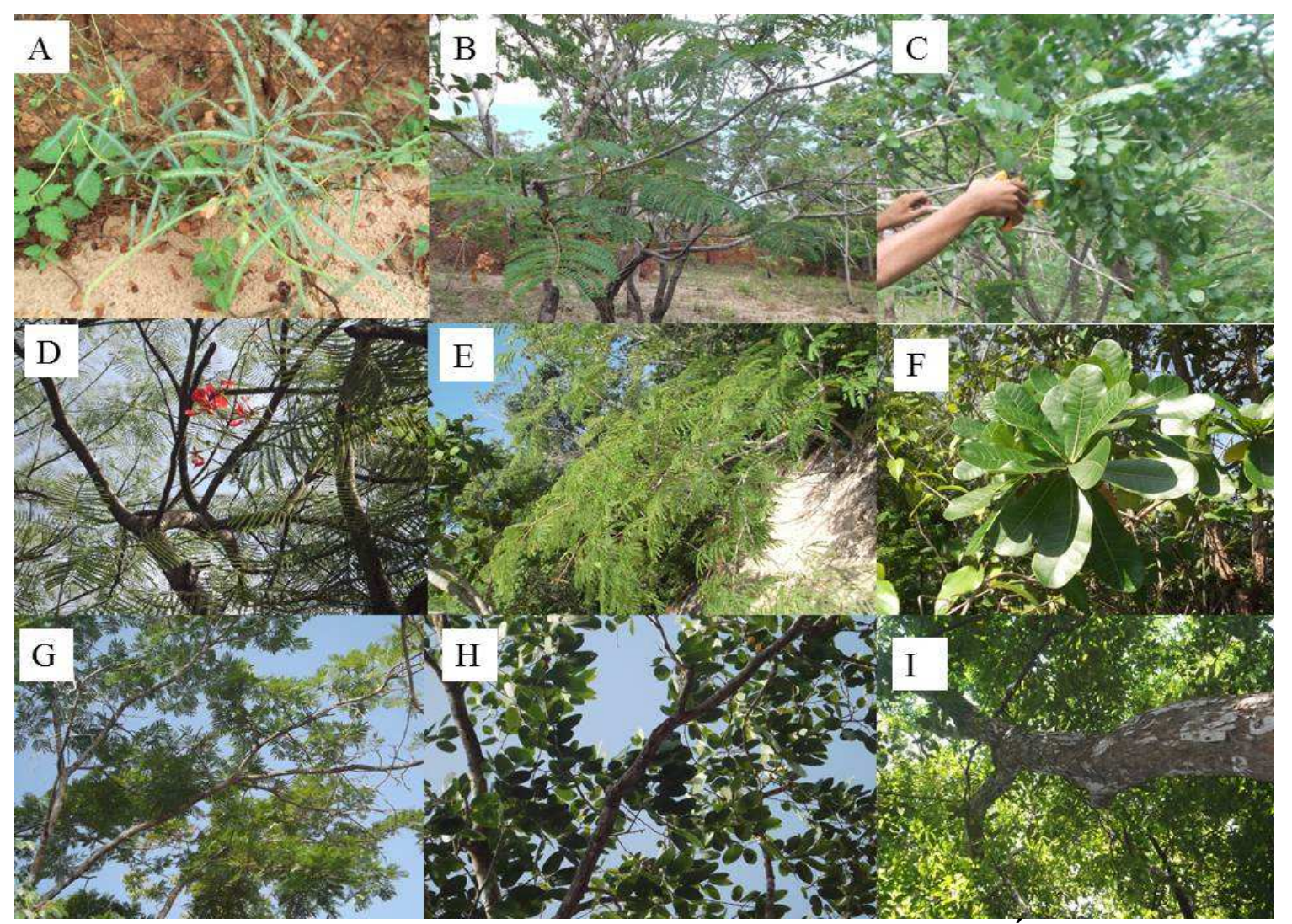

FIGURA 3. Espécies vegetais encontradas nas trilhas da Área de Proteção Ambiental Municipal do Inhamum. A) Aeschynomene histrix; B) Stryphnodendron coriaceum; C) Bodwichia virgilioides; D) Delonix regia; E) Platymenia reticulata; F) Himatanthus obovatus; G) Parkia platycephala; H) Hymenae stigonocarpa; I) Dalbergia miscolobium. Fonte: SILVA, G. S. 2016.

As trilhas ecológicas se apresentam por meio da Educação Ambiental como uma importante ferramenta que possibilita o contato do homem com a natureza, mostrando a importância dos seres bióticos e abióticos que constitui o ambiente (COSTA et al. 2012). Na concepção de LEFF (1999), quando se faz uma relação do uso da trilha como ferramenta pedagógica para contribuição da formação do cidadão se leva em conta que ela faz uma leitura e interpretação do ambiente natural 
subsidiando uma prática ambiental envolvendo desta forma a EA com foco na sustentabilidade.

Dentro do Programa de Política Nacional de Educação Ambiental (PRONEA), criado pela Lei Federal no 9.795/99 (BRASIL, 1999), as trilhas ecológicas foram regulamentadas como instrumento de educação no momento que coloca o indivíduo frente a frente com áreas de preservação, provocando nos mesmos, sentimentos de contemplação, apego e reflexões indo de encontro com os objetivos da Educação Ambiental (VASCONCELLOS, 2006).

\section{CONCLUSÃO}

O estudo das trilhas ecológicas da APA do Inhamum possibilitou um campo de estudo vasto em virtude da extensão e riqueza de espécies, bem como, dos atributos abióticos e estéticos com a perspectiva de promover atividades pedagógicas na garantia da difusão da prática da Educação Ambiental, como ferramenta de transformação de novas atitudes e comportamento quanto ao uso dos recursos naturais.

Vale ressaltar a importância do desenvolvimento de ações educativas na APA - Inhamum que contemplem os estudantes de todos os níveis de ensino com a perspectiva de promover momentos de reflexões e mudanças de comportamento sobre o respeito e ao valor do ambiente natural.

\section{REFERÊNCIAS}

ARANCÍBIA, S. D.; CAVALCANTE, A. M. B. Conservação da biodiversidade e da paisagem através de trilhas com sinalização para o ecoturismo, na Reserva Ecológica de Sapiranga, Ceará. Anais da 57aㅡ Reunião Anual da SBPC, Fortaleza: Anais, 2005.

ARAÚJO, F. A. S. A. Geomorfologia aplicada à fragilidade e ao zoneamento ambiental de Caxias/MA. Tese - Universidade Estadual Paulista Júlio de Mesquita Filho, Faculdade de Ciências e Tecnologia, Presidente Prudente, p. 185, 2012.

ARAUJO, S. M. V. G. As áreas de preservação permanente e a questão urbana. Consultoria Legislativa da área de Meio Ambiente. Direito Ambiental.. Brasília, DF: [s.n.], 2002. 12p.

BRASIL. Lei Federal n 9.795, de 27 de abril de 1999. Dispõe sobre a educação ambiental, institui a Política Nacional de Educação Ambiental e dá outras providências. Brasília, DF. Ministério do Meio Ambiente / MEC, 1999.

BRASIL. Lei Federal n. 9.985, de 18 de julho de 2000. Regulamenta o art. 225, $\S$ 10, incisos I, II, III e VII da Constituição Federal, institui o Sistema Nacional de Unidades de Conservação da Natureza e dá outras providências, 2000.

CAMARGO, A. L. B. As dimensões e os desafios do desenvolvimento sustentável: concepções, entraves e implicações à sociedade humana. Florianópolis, Dissertação (Mestrado em Engenharia de Produção) - Programa de Pós-Graduação em Engenharia de Produção, UFSC, p. 197, 2002. 
CARVALHO DE LIMA, T. D. Educação Ambiental e Sociedade. 2008. Disponível em: http://www.webartigos.com/artigos/educacao-ambiental-e-a-sociedade/11096/ Acesso em: 26/11/2016.

CAXIAS. Lei no 1.464/2001 de 04 de Julho de 2001. Dispõe sobre a Criação da Área de Proteção Ambiental (APA) Municipal do Inhamum e dá outras providencias. Prefeitura Municipal de Caxias, Estado do Maranhão, 2001.

CHAVES, A. D. C. G.; SANTOS, R. M. S.; SANTOS, J. O.; FERNANDES, A. A.; MARACAJÁ, P. B. A importância dos levantamentos florístico e fitossociológico para a conservação e preservação das florestas. Agropecuária Científica no Semiárido, v. 9, n. 2, p. 43-48, 2013.

COSTA, M. M. S; SILVA, E. B.; MENESES, L. F. Proposta de trilha ecológica como atrativo ecoturístico na área de proteção ambiental da barra do rio Mamanguape PB. Revista Turismo: Estudos e Práticas. v. 1, n. 2, p.104 - 107, 2012.

IKEMOTO, S. M. As trilhas interpretativas e sua relevância para a promoção da conservação: Trilha do Jequitibá, Parque Estadual dos Três Picos (PETP), RJ. Dissertação (Mestrado em Ciência Ambiental), Universidade Federal Fluminense, Niterói, p. 170, 2009.

LEFF, E. Educação ambiental e desenvolvimento sustentável. In: REIGOTA, M. Verde cotidiano: o meio ambiente em discussão. Rio de Janeiro: DP\&A, p. 148, 1999.

LIMA, J. C. S. O papel da Educação Ambiental na preservação do Meio Ambiente. Revista do CEDS. v.1, n.1, 2015.

MAGRO, T. C.; FREIXÊDAS, V.M. Trilhas: como facilitar a seleção de pontos interpretativos. Circular Interna IPEF, n.186, p. 10, 1998.

RODRIGUES, L. M.; TORVES, J. C. Manual do Curso de Condutor de Trilhas e Percursos Ecológicos. Escola de Agroturismo Sul. ASSOTUR- Associação de Turismo Estrada do Imigrante. 3 Léguas. Caxias do Sul, p. 15, 2007.

SERPE, B. M.; ROSSO, A. J. Uma leitura Piagetiana do papel da percepção na construção do conhecimento socioambiental em trilhas interpretativas. Revista Eletrônica de Psicologia e Epistemologia Genéticas, v. 3, n. 5, 2010.

SILVA, M. M.; NETO, T. A.; AZEVEDO, L. F. de, SCARTON, L. P.; HILLIG, C.Trilha ecológica como prática de educação ambiental. Revista Eletrônica em Gestão, Educação e Tecnologia Ambiental REGET/UFSM. v.5, n5, p. 705 - 719, 2012.

UNIVERSIDADE DO VALE DO PARAÍBA. Conhecer para Preservar. São José dos Campos: Univap, 2002.

VASCONCELLOS, J. M. de O. Educação e Interpretação Ambiental em Unidades de Conservação. Cadernos de Conservação. Curitiba, PR. v. 3, n 4. p. 86, 2006. 
YANO, O. Briófitas. In: FIDALGO, O.; BONONI, V. L. R. Técnicas de coleta, preservação e herborização de material botânico. Instituto de Botânica, São Paulo, p.27-30. 1984. 